\title{
Determinants of household catastrophic costs for drug sensitive tuberculosis patients in Kenya
}

Beatrice Kirubi ${ }^{1,2,3}$, Jane Ong'ang' ${ }^{4}$, Peter Nguhiu ${ }^{5}$, Knut Lönnroth ${ }^{1,2,3}$, Aiban Rono ${ }^{6}$ and Kristi Sidney-Annerstedt ${ }^{1,2,3^{*}}$ (D)

\begin{abstract}
Background: Despite free diagnosis and treatment for tuberculosis (TB), the costs during treatment impose a significant financial burden on patients and their households. The study sought to identify the determinants for catastrophic costs among patients with drug-sensitive TB (DSTB) and their households in Kenya.

Methods: The data was collected during the 2017 Kenya national patient cost survey from a nationally representative sample $(n=1071)$. Treatment related costs and productivity losses were estimated. Total costs exceeding $20 \%$ of household income were defined as catastrophic and used as the outcome. Multivariable Poisson regression analysis was performed to measure the association between selected individual, household and disease characteristics and occurrence of catastrophic costs. A deterministic sensitivity analysis was carried using different thresholds and the significant predictors were explored.
\end{abstract}

Results: The proportion of catastrophic costs among DSTB patients was $27 \%(n=294)$. Patients with catastrophic costs had higher median productivity losses, $39 \mathrm{~h}$ [interquartile range (IQR): 20-104], and total median costs of USD 567 (IQR: 299-1144). The incidence of catastrophic costs had a dose response with household expenditure. The poorest quintile was 6.2 times [95\% confidence intervals (CI): 4.0-9.7] more likely to incur catastrophic costs compared to the richest. The prevalence of catastrophic costs decreased with increasing household expenditure quintiles (proportion of catastrophic costs: 59.7\%, 32.9\%, 23.6\%, 15.9\%, and 9.5\%) from the lowest quintile (Q1) to the highest quintile (Q5). Other determinants included hospitalization: prevalence ratio $(P R)=2.8$ (95\% Cl: 1.8-4.5) and delayed treatment: $P R=1.5$ (95\% Cl: 1.3-1.7). Protective factors included receiving care at a public health facility: $P R=0.8$ (95\% Cl: 0.6-1.0), and a higher body mass index (BMI): $P R=0.97$ (95\% Cl: 0.96-0.98). Pre TB expenditure, hospitalization and BMI were significant predictors in all sensitivity analysis scenarios.

Conclusions: There are significant inequities in the occurrence of catastrophic costs. Social protection interventions in addition to existing medical and public health interventions are important to implement for patients most at risk of incurring catastrophic costs.

Keywords: Tuberculosis, Health expenditure, Income loss, Social protection, Kenya

*Correspondence: Kristi.sidney@ki.se

1 Department of Global Public Health, Karolinska Institutet, Stockholm, Sweden

Full list of author information is available at the end of the article

\section{Background}

Tuberculosis (TB) is a public health concern globally and a major cause of morbidity and mortality [1]. Globally, TB is the leading cause of death from a single infectious agent [1]. TB and poverty form a vicious cycle. TB original author(s) and the source, provide a link to the Creative Commons licence, and indicate if changes were made. The images or other third party material in this article are included in the article's Creative Commons licence, unless indicated otherwise in a credit line to the material. If material is not included in the article's Creative Commons licence and your intended use is not permitted by statutory regulation or exceeds the permitted use, you will need to obtain permission directly from the copyright holder. To view a copy of this licence, visit http://creativecommons.org/licenses/by/4.0/. The Creative Commons Public Domain Dedication waiver (http://creativeco mmons.org/publicdomain/zero/1.0/) applies to the data made available in this article, unless otherwise stated in a credit line to the data. 
disproportionately affects the poor [2]. Poverty increases the risk of TB infection associated with overcrowding, malnutrition and poor sanitation [3,4]. On the other hand, poor patients face barriers in accessing care, resulting in more severe disease and inability to work $[2,5]$. As a result, households may engage in coping mechanisms such as dissaving, i.e. selling assets or seeking loans to support their treatment, causing further impoverishment [6-8] perpetuating the medical poverty trap [9].

The World Health Organization (WHO) End TB Strategy aims to end the global TB epidemic [10]. The strategy identifies one of the key targets as reducing the number of TB-affected households facing catastrophic costs to zero [10]. WHO developed a TB Patient Cost Survey (PCS) manual/workbook that guides assessment of costs relative to household income, and estimates the proportion of patients experiencing catastrophic costs, exceeding a threshold of $20 \%$ of household income [10, 11]. Catastrophic costs are also associated with adverse TB outcomes such as loss to follow up, low uptake of preventive treatment for contacts, low HIV testing rates or even death [12].

In order to address equitable financial protection for TB patients, there is need to extend coverage of mitigative interventions for patients with TB. The poor and patients with drug resistant $\mathrm{TB}$ are more vulnerable to higher costs due to TB $[7,12,13]$. Patients with drug resistant TB (DRTB) tend to experience higher treatment costs associated with more severe disease manifestation, prolonged treatment and treatment strategies and are therefore in need of special support to reduce the risk of catastrophic costs $[7,13,14]$. While drug-sensitive TB (DSTB) disease is less fatal and has considerably less costs compared to DRTB patients, the sheer number of patients is high, with significant societal implications of catastrophic costs [1]. Consequences of incomplete DSTB treatment include failed treatment, developing drug resistance, heavy economic and social burden on affected households and even death $[15,16]$.

Kenya is one of the top 20 countries contributing to the highest burden of TB, TB/HIV co-infection and DRTB globally [1]. The Kenya national TB prevalence survey conducted in 2015, estimated a TB prevalence of 558 cases per 100000 population [17]. The disease disproportionately affects productive age groups, males and those residing in the urban areas $[1,17]$. A summary of the country disease burden is described in Additional file 1 .

$\mathrm{TB}$ services are provided at all levels of the healthcare system. Fifty-eight percent of DSTB patients initiated care at primary healthcare facilities [18]. The referral pathways ensure that sicker patients are treated in higher level facilities [19]. The TB treatment model is predominantly community DOTS with planned visits to the facility [15]. In the intensive phase, the patient has two weekly visits, which is less frequent in the continuation phase. This may differ for patients whose condition deteriorates, develop severe side effects or have other comorbidities. Patients who require critical care are hospitalized for inpatient care until they are stable to continue treatment at home.

The National TB Programme (NTP) provides TB diagnosis through sputum examination and anti-TB medicines at no cost to the patient [19]. This excludes radiological examinations (X-Rays) [19]. The private sector also plays a key role in TB service delivery [18]. Between 2013 and 2017, 20\% of TB patients received care in private hospitals [20]. The private sector includes for profit hospitals, faith-based organizations (FBOs), and non-governmental organizations (NGOs). The NTP supports patients in private facilities through subsidized diagnosis and free medicines, as in public hospitals [19]. However, the cost of other complementary tests and treatment is borne by the patient.

In 2016, Kenya conducted the first national TB PCS to establish the costs incurred by TB patients and their households, from the onset of TB illness to treatment completion [21]. The survey estimated that $27 \%$ of all TB patients incurred catastrophic costs [21]. When considering only those with drug-resistant TB, $86 \%$ incurred catastrophic costs.

Social support interventions for TB patients in Kenya exclude those with DSTB. The NTP prioritizes DRTB patients for support through cash transfers and health insurance [22]. This is limited; corresponding to 470 DRTB patients out of 95000 TB cases notified in Kenya in 2018 [1]. Following the Kenya PCS, consultations on the need to extend this coverage led to the development of the TB social protection policy targeting patients with DSTB [23].

In the context of limited resources, there is need to prioritize DSTB patients and households who are most vulnerable to catastrophic costs for targeted interventions. However, given resource constraints, there may be a need for special targeting patients who have DSTB. There is a gap in identifying predictors for catastrophic costs among patients on treatment for DSTB. While, several PCSs have reported the determinants of catastrophic costs for different countries [21, 24], they often combine all patients [21] or only consider costs incurred in the pre-diagnosis period [24]. Identifying the predictors for catastrophic costs among DSTB patients, would be the first step in detecting vulnerable households. Hence the aim of this study was to identify the determinants for 
catastrophic costs among patients with drug-sensitive TB (DSTB) and their households in Kenya.

\section{Methods \\ Study setting}

Kenya is a lower, middle-income country with a population of more than 47 million, of whom $69 \%$ reside in rural areas [25]. The country's gross domestic product (GDP) per capita is US Dollar (USD) 1710 [26]. With a Gini coefficient of 0.4 , about $36 \%$ of the population lives below the international poverty line, spending less than USD 1.9 per day (19). In 2018, the human development index (HDI) was estimated at 0.58 placing it in the medium human development category [27]. The country is administratively divided into 47 counties, with varying population density, and further into sub-counties for service provision $[25,28]$. The health care delivery system including the TB service provision follows the administrative structure with referral mechanisms in place [28].

The first Kenya national patient cost survey was conducted in 2016 [21]. The sample was nationally representative and included patients from 111 pre-selected health facilities of 30 counties [21]. The data was collected between May and June 2017, using a structured questionnaire adapted from the WHO costing tool [11]. A more detailed description of the survey recruitment, methods and results is available elsewhere [21]. This national survey provides the data for our study.

\section{Study design and population}

The study design involved a secondary analysis of quantitative data. The data included all DSTB patients (adults and children) collected during the 2016 Kenya national TB PCS in the dataset [21]. The study excluded patients who had not completed two weeks in the reported phase of treatment and those on treatment for DRTB. Prior to data extraction, we developed a list of possible variables to enable us to answer the research question based on literature. We used the Kenya PCS questionnaire and selected the list of variables found in the database. The available data was based on the TB category group and the phase of treatment (see Additional file 2).

\section{Cost measures}

The study outcome variable was the binary presence of catastrophic costs. To determine catastrophic costs, the proportion of annual household expenditure spent on total TB related costs (direct and indirect costs) was calculated. The cost was considered catastrophic when this proportion exceeded the threshold of $20 \%$ [10]. Operational definitions of key concepts of TB disease, treatment and costs as used in this study are described in the glossary (Box 1).

\section{Box 1 Glossary of operational definitions for tuberculosis disease, treatment and costs}

Patient registration group: Classification of TB based on history of previous TB treatment

New case: Patient who has never been treated for TB before

Retreatment case: Patient treated with anti-TB drugs in the past and are now on treatment after the following

- Relapse (previously completed treatment/cured)

- Treatment failure (last treatment failed at the end of treatment)

- Loss to follow up (patients who did not complete their last treatment)

TB treatment phases:

Intensive phase: the first two consecutive months of TB treatment

Continuation phase: the four consecutive months immediately following the intensive treatment phase

During treatment: the period of time spanning from the beginning of the intensive treatment phase to the end of continuation treatment phase

Model of care:

Community Directly Observed Treatment Strategy (DOTS): Patient receives ambulatory care; collects medicine from the health facility biweekly or weekly

Facility based DOTS: Patient receives medicine at the health facility under observation, usually on a daily basis

Hospitalization: Patient is treated as an inpatient until symptoms are stabilized

DOTS supporter/treatment supporter:

Refers to person, often family member who accompanies the patient to the hospital or stays with the patient during a hospitalization event. Could also be the DOTS supporter i.e. observes/reminds patient to take medicine at the specified time

Treatment delay:

Time between the onset of symptoms and the start of treatment. For this study the threshold is 4 weeks

TB costs

- Direct medical costs: costs of medical examinations and medicines, including hospitalization

- Direct non-medical expenses: costs of, TB-care-related transport, accommodation, natural remedies and other miscellaneous expenses. Also includes costs incurred by guardian or treatment supporter

- Direct costs: the sum of the direct medical costs and direct non-medical costs (above)

- Lost income (indirect costs): the income the patient estimated that the household lost due to TB illness or when seeking care/treatment. This also includes costs incurred from onset of symptoms and prior to presentation for TB diagnosis

- Total costs: direct costs plus lost income

Household $(H H)$ :

People that live together under the same roof, often with family relations, and share at least one meal a day

A patient's perspective was assumed in the estimation of total costs. Direct costs were a total of patient medical costs, patient non-medical costs and guardian and/or treatment supporter costs. Medical costs included consultation fees, payment for laboratory and imaging tests, hospitalization costs and any out-of-pocket (OOP) costs incurred towards purchasing drugs. Non-medical direct costs included OOP payments for travel costs, accommodation costs, food supplements, traditional medicine 
Table 1 A summary of exposure variables and their measures

\begin{tabular}{|c|c|c|c|c|}
\hline Type of data & Category & Variable & Definition & Measure \\
\hline \multirow[t]{4}{*}{ Continuous } & Individual characteristics & Age & $\begin{array}{l}\text { Age of patient in years } \\
\text { rounded off to the next } \\
\text { whole unit }\end{array}$ & Years \\
\hline & & $\mathrm{BMI}$ & Nutritional status of patient & $\begin{array}{l}\text { Body weight } \\
\text { (kilograms)/height }^{2} \text { (metres) }\end{array}$ \\
\hline & $\begin{array}{l}\text { Household } \\
\text { characteristics }\end{array}$ & Household size & $\begin{array}{l}\text { Total number of people } \\
\text { living together and shar- } \\
\text { ing at least one meal/day } \\
\text { (usually dinner) }\end{array}$ & Units \\
\hline & & Pre-TB expenditure & $\begin{array}{l}\text { Total annual household } \\
\text { expenditure (patient and/ } \\
\text { or others) prior to falling } \\
\text { ill with TB }\end{array}$ & \\
\hline \multirow[t]{13}{*}{ Categorical } & Individual characteristics & Gender & Gender of patient & Male/Female \\
\hline & & Diabetes & $\begin{array}{l}\text { Type II diabetes mellitus as a } \\
\text { comorbidity }\end{array}$ & Yes/No \\
\hline & & HIV status & Presence of HIV coinfection & Yes/No/Undisclosed \\
\hline & & Education & Patient's level of education & $\begin{array}{l}\text { No education, primary edu- } \\
\text { cation or lower ( }<8 \text { years), } \\
\text { secondary education } \\
\text { and above }=>8 \text { years in } \\
\text { school }\end{array}$ \\
\hline & & Nutritional Support & $\begin{array}{l}\text { Receiving nutritional sup- } \\
\text { port }\end{array}$ & Yes/No \\
\hline & Household characteristics & Residence & Living in urban/rural area? & Urban/Rural \\
\hline & & Insurance status & $\begin{array}{l}\text { Does the patient have } \\
\text { health insurance cover- } \\
\text { age? }\end{array}$ & $\begin{array}{l}\text { No/Social health insurance/ } \\
\text { Private health Insurance }\end{array}$ \\
\hline & $\begin{array}{l}\text { Disease \& care-seeking } \\
\text { characteristics }\end{array}$ & X-ray test & $\begin{array}{l}\text { Radiography test done for } \\
\text { diagnosis of TB }\end{array}$ & Yes/No \\
\hline & & Hospitalized & $\begin{array}{l}\text { Any hospitalization during } \\
\text { current TB treatment }\end{array}$ & Yes/No \\
\hline & & TB type & $\begin{array}{l}\text { Disease affecting the chest } \\
\text { or another body organ? }\end{array}$ & Pulmonary/Extrapulmonary \\
\hline & & Facility type & $\begin{array}{l}\text { Type of health facility giving } \\
\text { care }\end{array}$ & Public/Private \\
\hline & & Retreatment & $\begin{array}{l}\text { First episode of treatment } \\
\text { or not? }\end{array}$ & New/Retreatment \& Relapse \\
\hline & & Treatment delay & $\begin{array}{l}\text { Length of the delay } \\
\text { between onset of } \\
\text { symptoms and start of } \\
\text { treatment }\end{array}$ & $\begin{array}{l}<4 \text { weeks } / 4 \text { weeks or more } \\
\text { delay }\end{array}$ \\
\hline
\end{tabular}

$B M I$ body mass index, $T B$ tuberculosis

and costs for services provided by traditional healers. Guardian and treatment supporter costs included OOP payments for transport, accommodation and valuation of time lost. Time lost was valued using the human capital approach by multiplying total hours lost by patient due to the illness or for TB care by the hourly wage calculated from the reported income. The 2017 Kenyan government stipulated minimum wage was adopted when no income was reported. The patient's valuation of productivity loss was considered as indirect costs [11].
A two-step procedure was used to calculate the costs. First, the two-week estimates reported from the survey were scaled up to estimate the costs and time loss for the treatment phase at the time of the interview. Since patient costs were only available for one phase of treatment, cost for missing phase were then estimated using cost data from the patients in the alternative phase. Costs were extrapolated based on the median costs incurred by the patients in the treatment phase in question at the time of the interview. Hence, the cost and time lost 
Table 2 Participant characteristics by occurrence of catastrophic costs at 20\% threshold, Kenya $2016(n=1071)$

\begin{tabular}{|c|c|c|c|c|c|c|c|c|}
\hline & \multicolumn{2}{|l|}{ Characteristics } & \multirow[t]{2}{*}{$\begin{array}{l}\text { Total } \\
n=1071\end{array}$} & \multicolumn{2}{|c|}{$\begin{array}{l}\text { With catastrophic costs* } \\
n=294\end{array}$} & \multicolumn{2}{|c|}{$\begin{array}{l}\text { without catastrophic costs* } \\
n=777\end{array}$} & \multirow[t]{2}{*}{$P$-value*** } \\
\hline & & & & $n$ & $\% * *$ & $n$ & $\% * *$ & \\
\hline \multirow[t]{3}{*}{ Patient factors } & Gender & Female & 406 & 117 & 39.8 & 289 & 37.2 & \\
\hline & & Male & 665 & 177 & 60.2 & 488 & 62.8 & 0.457 \\
\hline & Age & Mean (SD) & & 31 & 18.1 & 31 & 15.1 & $0.698^{\ddagger}$ \\
\hline \multirow{10}{*}{$\begin{array}{l}\text { Household } \\
\text { character- } \\
\text { istics }\end{array}$} & $\begin{array}{l}\text { Formal education } \\
\text { level }\end{array}$ & $\begin{array}{l}\text { Secondary \& } \\
\text { above }\end{array}$ & 547 & 155 & 52.7 & 392 & 50.5 & \\
\hline & & $\begin{array}{l}\text { Primary school } \\
\& \text { below }\end{array}$ & 397 & 92 & 31.3 & 305 & 39.3 & \\
\hline & & None & 127 & 47 & 16.0 & 80 & 10.3 & $0.089^{\dagger}$ \\
\hline & Health insurance & None & 905 & 247 & 84.0 & 658 & 84.7 & \\
\hline & & Private & 18 & 6 & 2.1 & 12 & 1.5 & \\
\hline & & $\begin{array}{l}\text { National } \\
\text { Health Insur- } \\
\text { ance }\end{array}$ & 148 & 41 & 13.9 & 107 & 13.8 & $0.836^{\dagger}$ \\
\hline & Residence & Rural & 265 & 71 & 24.1 & 194 & 25.0 & \\
\hline & & Urban & 806 & 223 & 75.9 & 583 & 75.0 & 0.252 \\
\hline & Household size & Median (IQR) & & 4 & $(2-6)$ & 4 & $(2-6)$ & $0.365^{\dagger}$ \\
\hline & $\begin{array}{l}\text { Annual house- } \\
\text { hold income } \\
\text { (USD) }\end{array}$ & Median (IQR) & & 1374 & (714-2509) & 3081 & (1918-5279) & $<0.001^{\dagger}$ \\
\hline \multirow{22}{*}{$\begin{array}{l}\text { Disease and } \\
\text { care-seeking } \\
\text { character- } \\
\text { istics }\end{array}$} & TB type & $\begin{array}{l}\text { Extra-pulmo- } \\
\text { nary }\end{array}$ & 188 & 63 & 21.4 & 125 & 16.1 & \\
\hline & & Pulmonary & 883 & 231 & 78.6 & 651 & 83.9 & 0.018 \\
\hline & $\mathrm{BMI}(n=852)$ & Mean (SD) & & 14 & 8.3 & 16 & 7.9 & $0.023^{\ddagger}$ \\
\hline & HIV status & Negative & 278 & 81 & 27.6 & 197 & 25.4 & \\
\hline & & Positive & 769 & 203 & 69.4 & 566 & 72.8 & \\
\hline & & Unknown & 24 & 10 & 3.4 & 14 & 1.8 & 0.272 \\
\hline & Diabetes status & Yes & 20 & 5 & 1.7 & 15 & 1.9 & \\
\hline & & No & 1028 & 283 & 96.3 & 745 & 95.9 & \\
\hline & & Unknown & 23 & 6 & 2.0 & 17 & 2.2 & 0.568 \\
\hline & Treatment cat- & New case & 953 & 259 & 88.1 & 684 & 88.0 & \\
\hline & egory & $\begin{array}{l}\text { Relapse/ } \\
\text { retreatment }\end{array}$ & 128 & 35 & 11.9 & 93 & 12.0 & 0.877 \\
\hline & Facility of treat- & Private & 102 & 35 & 11.9 & 67 & 8.6 & \\
\hline & & Public & 969 & 259 & 88.1 & 710 & 91.4 & 0.102 \\
\hline & Treatment & Yes & 180 & 70 & 23.8 & 110 & 14.2 & \\
\hline & delay > 4 weeks & No & 891 & 224 & 76.2 & 667 & 85.8 & 0.002 \\
\hline & Hospitalization & Yes & 6 & 5 & 1.7 & 1 & 0.1 & \\
\hline & & No & 1065 & 289 & 98.3 & 776 & 99.9 & 0.048 \\
\hline & X-ray done & Yes & 589 & 180 & 61.2 & 409 & 52.6 & \\
\hline & & No & 482 & 114 & 38.8 & 368 & 47.4 & 0.114 \\
\hline & Received nutri- & Yes & 713 & 192 & 65.3 & 521 & 67.1 & \\
\hline & tional support & No & 354 & 100 & 34.0 & 254 & 32.7 & \\
\hline & & Unknown & 4 & 2 & 0.7 & 2 & 0.7 & 0.193 \\
\hline
\end{tabular}

*Where indicated by row title, it represents mean or median, **Where indicated by row title, this represents standard deviation (SD), or interquartile range (IQR), ***Pearson's Chi Square test for comparison of proportions unless specified

† Mann Whitney test

${ }^{\ddagger} t$-test for comparison of means 


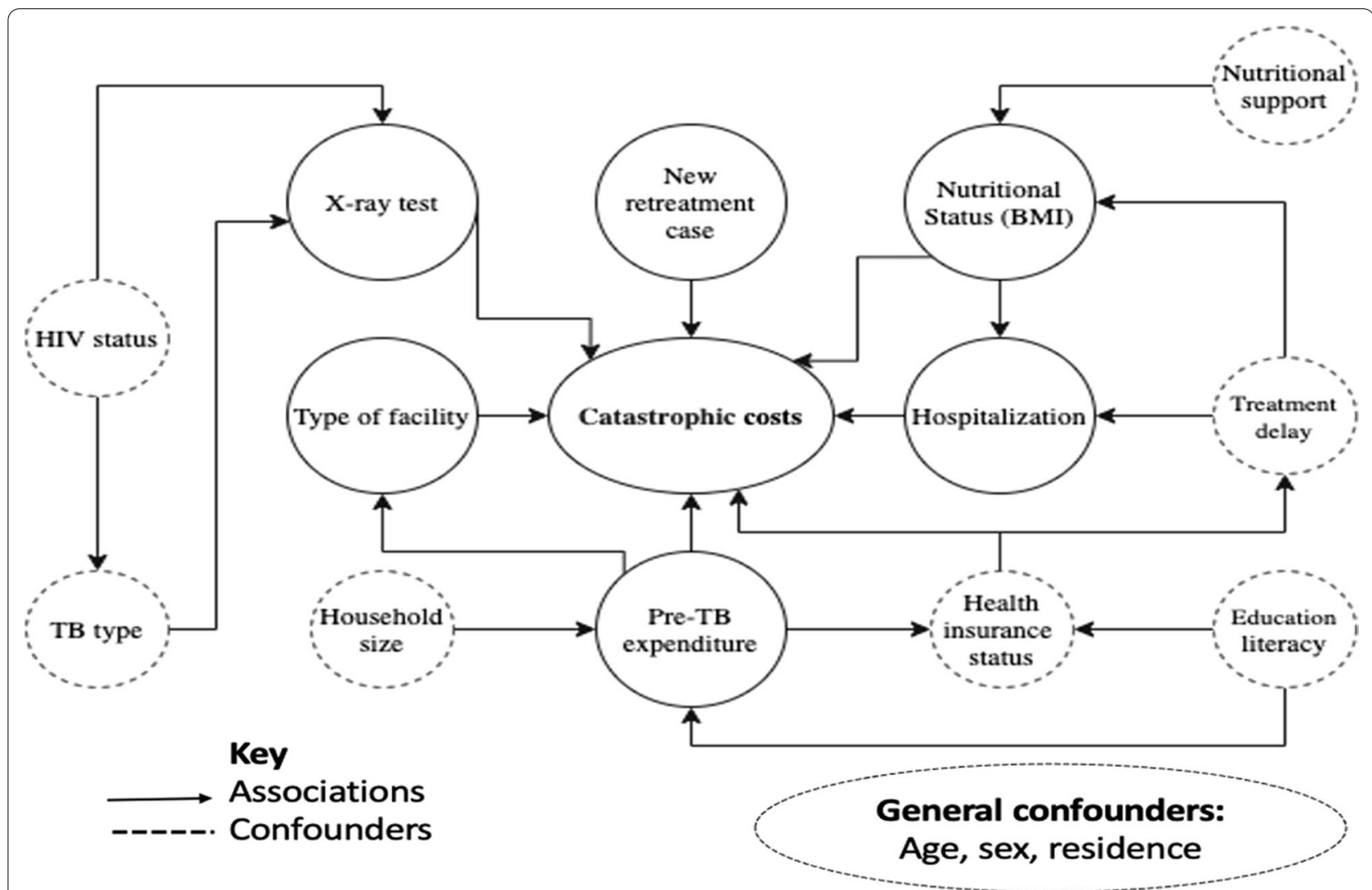

Fig. 1 Conceptual framework of selected exposure variables and proposed associations based on the literature

information for those in intensive phase, were used to project intensive phase costs for those interviewed in the continuation phase and vice versa for those in the intensive phase. The mean imputation approach was used to handle missing data [29].

To estimate the annual household expenditure, a consumption approach was used based on self-reported amounts spent on selected goods and services such as food items, non-food items, durable goods and housing [11]. This approach was selected as many participants do not have a formal income. The total household expenditure was converted to the USD 2020 value [30,31].

Recognizing the inadequacies of data collected during a cross-sectional survey, several assumptions were made in order to determine the costs incurred, productivity losses and household expenditure (Box 2).

\section{Box 2 List of assumptions for the estimation of costs}

Regarding the patient condition:

1. That all patients remained in the same treatment category (DSTB) until the end of their current treatment

2. That all patients adhered to the NTP recommended visit schedule for the duration of treatment (biweekly in intensive phase and once a month in the continuation phase)
3. No further hospitalization episodes happened after the interview Regarding the estimation of costs:

4. The costs incurred by patients interviewed in intensive phase were similar to those incurred previously by those interviewed in continuation phase given similar characteristics: demographic, disease and treatment categories, and socioeconomic characteristics. These characteristics were used to estimate costs and productivity losses for the alternative (missing) phase of treatment

5. Likewise, costs incurred by patients interviewed in continuation phase were similar to those to be incurred in future by those interviewed in the Intensive phase given some similar characteristics as above

6. That the costs and productivity losses remained constant for the entire treatment phase

7. Where the patient was a child, the costs and productivity losses considered were those of the parent or primary guardian who was also assumed to be the treatment supporter

8. To value the time lost by guardians and treatment supporters using human capital approach, it was assumed that all workers earned the 2017 Kenya government stipulated minimum wage; which is standardized by urban or rural residence

9. Household expenditure remained constant despite income changes due to TB [32]

10. Discounting was not taken into consideration since the time horizon is 1 year

DSTB drug-sensitive tuberculosis, NTP National TB Programme, TB tuberculosis 
Table 3 Costs and time loss by occurrence of catastrophic costs, Kenya 2016

\begin{tabular}{lcccc}
\hline Variable* & $\begin{array}{l}\text { All participants } \pm \\
(\boldsymbol{n}=\mathbf{1 0 7 1 )} \\
\text { median (IQR) }\end{array}$ & $\begin{array}{l}\text { With catastrophic costs } \\
\boldsymbol{( n = 2 9 4 )} \\
\text { median (IQR) }\end{array}$ & $\begin{array}{l}\text { Without catastrophic } \\
\text { costs } \\
(\boldsymbol{n}=\mathbf{7 7 7}) \\
\text { median (IQR) }\end{array}$ & $\boldsymbol{P}_{\text {-value*** }}$ \\
\hline Time loss (hours) & $29(17-57)$ & $39(20-104)$ & $27(16-47)$ & $<0.001$ \\
Medical costs & $11(0-44)$ & $25(1.53-100)$ & $9(0-37)$ & $<0.001$ \\
Non-medical costs & $173(78-345)$ & $306(159-651)$ & $136(59-285)$ & $<0.001$ \\
Indirect costs & $36(22-66)$ & $49(25-139)$ & $33(21-57)$ & $<0.001$ \\
Total costs & $270(141-502)$ & $567(299-1149)$ & $212(120-373)$ & $<0.001$ \\
\hline
\end{tabular}

*All costs in USD, 2020; **Mann-Whitney test

\section{Data analysis}

The exposure variables were selected based on existing literature. Several complex relationships of covariates exist based on previous literature as depicted in Fig. 1.

The exposure variables were grouped into three categories: individual, household, and disease and care-seeking characteristics [21, 33-35]. Individual factors describe the patient characteristics, household factors describe characteristics that are influenced by their next of kin or who they live with and TB related characteristics are related to the disease type, severity and treatment. The exposure variables are described in further detail in Table 1.

The variables age and BMI were treated as continuous variables for the analysis. Pre-TB household expenditure variable was divided into quintiles in order to demonstrate the dose response relationship between the economic status and catastrophic costs. The mean imputation approach was used for missing variables related to the patient costs [29].

To define the participant characteristics, descriptive statistics [i.e. mean, standard deviation (SD), median, interquartile ranges (IQR) and proportions] were used. A comparison of patients who incurred catastrophic costs and those without catastrophic costs was conducted using Pearson's chi square, Fishers test, Student's $t$ test and Mann-Whitney test as appropriate. Statistical significance was defined as $P<0.05$. The analysis took into account sampling weights used for the Kenya PCS to adjust for clustering effects related to the sampling method [21]. Data analysis was done using Stata statistical software 15 (College Station, TX: StataCorp LLC) [36].

Univariable regression analysis was used describe the association between the individual exposure variables and the outcome variable (occurrence of catastrophic costs). We investigated correlations between selected exposure variables. Multivariable regression was then carried out to estimate the adjusted prevalence ratio (PR) as a measure of risk [37, 38]. Three confounders: age, sex and residence, were adjusted for in the multivariable regression model. Since the occurrence of catastrophic costs was high (27\%), Poisson's regression with robust variance was used to $[39,40]$ give an accurate estimation and interpretation of risk [39-42]. Adjusted prevalence ratios and 95\% confidence intervals $(C I)$ were derived from the final model. Similarly, an alpha of $<0.05$ was considered statistically significant. Post estimation tests were performed to assess the predictive model. Variance inflation factors (VIF) (below 10) was used to assess for multicollinearity. Goodness of fit using the Pearson's chisquare test with an alpha of $<0.05$ was considered significant to reject the model.

A deterministic sensitivity analysis was done using different thresholds (10\% and $40 \%)$ to measure catastrophic costs, and a conservative estimate of the patients' direct costs (excluding lost income) [11, 43, 44]. For the alternative scenarios, the analysis estimated the occurrence of catastrophic costs and the significant determinants after regression.

\section{Results \\ Participants}

A total of 1071 participants were included in the study after excluding 296 patients with DRTB and 130 patients who were ineligible (Fig. 2).

\section{Participants baseline characteristics}

The mean age of the participants was 31 years, with $15 \%$ $(n=161)$ being children under 15 years. Males formed the majority of the respondents $(n=665,62 \%)$. One out of ten participants had no formal education $(n=127)$; and a majority had no insurance coverage $(n=905,85 \%)$ (Table 2).

The socio-demographic characteristics were similar for participants with and without catastrophic costs, except 


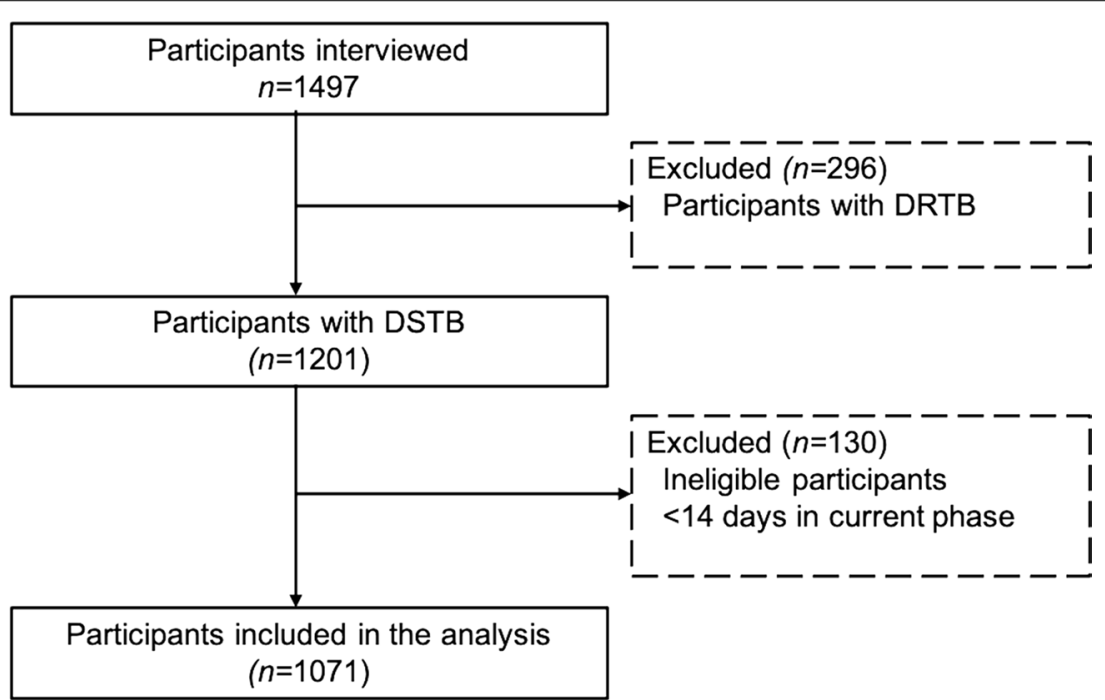

Fig. 2 Flow chart detailing participant inclusion. DSTB drug-sensitive tuberculosis; DRTB drug-resistant tuberculosis

for the expenditure capacity prior to TB illness (Table 2). The participants with catastrophic costs had lower median pre-TB household expenditure USD 1374 (IQR: 714-2509) vs median USD 3081 (IQR: 1918-5279) for those without. There is a significant dose effect relationship between pre-TB household expenditure quintiles and the occurrence of catastrophic costs (lowest quintile: $59.7 \%$, 2nd lowest quintile: $32.9 \%$, middle quintile: $23.6 \%$, 2nd highest quintile: $15.9 \%$, and for the highest wealth quintile: $9.5 \%$ ).

A comparison of the disease and care-seeking characteristics revealed significant differences for the type of $\mathrm{TB}, \mathrm{BMI}$, hospitalization events and the treatment delay (Table 2). The participants with catastrophic costs had a lower nutritional status (mean BMI: 14 vs 16). Further, the subgroup with catastrophic costs had a higher proportion of participants with prolonged treatment delay ( $26 \%$ vs $14 \%$ ). While only $1 \%$ of patients were hospitalized during treatment $(n=6)$, a majority of those hospitalized $(n=5,83 \%)$ incurred catastrophic costs.

\section{Cost consequences and time loss}

Participants incurred a median total cost of USD 270 (IQR: 141-502) from the onset of disease till completion of treatment (Table 3). Non-medical expenses accounted for the majority of costs, median USD 173 (IQR: 78-345). A median expenditure of USD 11 (IQR: 0-44) went towards medical costs. Patients spent a median of $29 \mathrm{~h}$ for TB care including time spent seeking care in the prediagnosis phase (IQR: 17-57). When time was valued, the median indirect costs were USD 36 (IQR: 22-66) (Table 3).
Participants with catastrophic costs incurred significantly higher costs and time losses (Table 3 ). The total median costs were USD 567 (IQR: 299-1149) for those with catastrophic costs compared to USD 212 (IQR: 120-373) among those without catastrophic costs. The median costs for the participants with catastrophic costs had a wide distribution (Fig. 3).

Low household pre-TB expenditure, being hospitalized and having a chest X-Ray examination were associated with a higher prevalence of catastrophic costs. Conversely, a better nutritional status and having pulmonary disease (PTB) was associated with a lower risk of catastrophic costs (Table 4).

After adjusting for potential confounders and covariates, household expenditure quintiles (pre-TB), hospitalization, treatment delay were associated with a higher incidence of catastrophic costs (Table 4). Lower pre-TB household expenditure was associated with a higher incidence of catastrophic costs. The lowest quintile was 6 times more likely (95\% CI: 4.0-9.7) to incur catastrophic costs compared to the wealthiest quintile. Being hospitalized during TB treatment had a PR of 2.8 (95\% CI: 1.8-4.5). Treatment delay of more than four weeks was associated with a PR of 1.5 PR (95\% CI: 1.3-1.7). Seeking care in a public facility and a higher BMI were protective against incurring catastrophic costs with PR of 0.8 (95\% CI: 0.6-1.0) and 0.97 (95\% CI: $0.96-0.98)$ respectively (Table 4). The graph below depicts the association between covariates and the PR of incurring catastrophic costs (Fig. 4).

There were significant associations between the covariates (Fig. 4). The type of TB was associated with having an X-ray [(Phi coefficient, Phi $)=0.2, P<0.001$ ]. 
Table 4 Univariable and multivariable Poisson regression of factors associated with catastrophic costs, Kenya patient costs survey (2016)

\begin{tabular}{|c|c|c|c|c|}
\hline $\begin{array}{l}\text { Variable } \\
(n=1071)\end{array}$ & $\begin{array}{l}\text { Unadjusted prevalence ratio } \\
(95 \% \mathrm{Cl})\end{array}$ & $P$-value & $\begin{array}{l}\text { Adjusted prevalence ratio*** } \\
(95 \% \mathrm{Cl})\end{array}$ & $P$-value*** \\
\hline $\begin{array}{l}\text { Hospitalization (ref = not hospi- } \\
\text { talized) }\end{array}$ & $3.1(2.1-4.4)$ & $<0.001$ & $2.8(1.8-4.5)$ & $<0.001$ \\
\hline $\begin{array}{l}\text { Treatment delay } \\
\quad(\text { ref }=<4 \text { weeks })\end{array}$ & $1.6(1.2-1.9)$ & $<0.001$ & $1.5(1.3-1.7)$ & $<0.001$ \\
\hline $\begin{array}{l}\text { Type of facility offering treat- } \\
\text { ment } \\
\text { (ref = private) }\end{array}$ & $0.8(0.6-0.9)$ & 0.032 & $0.8(0.6-0.9)$ & 0.021 \\
\hline BMI & $0.98(0.97-0.99)$ & $<0.001$ & $0.97(0.96-0.98)$ & $<0.001$ \\
\hline \multicolumn{5}{|l|}{$\begin{array}{l}\text { Pre-TB HH exp_quintiles } \\
\text { (ref = Quintile 5) }\end{array}$} \\
\hline Poorest Q1 & $6.3(3.9-10.3)$ & $<0.001$ & $6.2(4.0-9.7)$ & $<0.001$ \\
\hline Q2 & $3.40(2.1-5.6)$ & $<0.001$ & $3.4(2.1-5.3)$ & $<0.001$ \\
\hline Q3 & $2.5(1.4-4.2)$ & 0.002 & $2.4(1.5-3.9)$ & $<0.001$ \\
\hline Q4 & $1.7(0.9-3.2)$ & 0.111 & $1.6(0.9-3.0)$ & 0.110 \\
\hline TB type $\left(r e f=E^{2} T^{\dagger}\right)$ & $0.8(0.6-1.0)$ & 0.050 & & \\
\hline X-ray test (ref $=$ no X-Ray) & $1.3(1.1-1.56)$ & 0.018 & $1.1(0.9-1.4)$ & 0.147 \\
\hline Constant & & & 0.19 & $<0.001$ \\
\hline
\end{tabular}

Household expenditure was associated for nutritional status (Cramer's $\mathrm{V}=0.11, P=0.014$ ) and having an $\mathrm{X}$-ray (Cramer's $\mathrm{V}=0.16, P<0.001)$. Seeking care at a private hospital was associated with hospitalization $($ Phi $=0.14, P<0.001)$.

\section{Sensitivity analysis}

Hospitalization, household expenditure and BMI were significant determinants for catastrophic costs in the different scenarios, with changes in the strength of association (PR) (Table 5).

At $10 \%$ threshold, $54 \%$ of the participants incurred catastrophic costs $(n=582)$. At $40 \%$ threshold however, $13 \%$ $(n=137)$ incurred catastrophic costs and increasing age was an additional predictor. The conservative estimate, using only direct costs had a similar profile for determinants while $21 \%(n=224)$ incurred catastrophic costs.

\section{Discussion}

Recognizing the determinants of catastrophic costs could provide an insight into approaches for mitigating catastrophic costs among the vulnerable TB patients and their households. This study confirms that a significant proportion of patients with DSTB (27\%) incur catastrophic costs, despite free TB diagnosis and treatment. Further, it demonstrates the association between incurring catastrophic costs and poverty, disease severity and delayed treatment initiation. Low economic status is the most significant factor associated with incurring catastrophic costs. Patients who experience catastrophic costs have a lower economic status (pre-TB) and incur higher costs and productivity losses in relation to economic capacity. Patients with severe disease requiring inpatient care, and those who experience delay before treatment are also at a higher risk of incurring catastrophic costs. On the other hand, seeking care at a public health facility and a better nutritional status are protective factors.

\section{Catastrophic costs and poverty}

Being poor prior to TB illness is associated with the highest incidence of catastrophic costs, resulting in the medical poverty trap. Using household expenditure quintiles in this study demonstrates the higher risk associated with the decreasing economic status. This finding is similar to previous studies in other low- and middle-income settings like Uganda [24], Benin [35] Malawi [45] and China [34]. These findings are also in line with Barasa et al. when considering OOP expenditure for general illness in Kenya [46]. The median age of this study is 31 years representing a young productive age-group. Hence catastrophic costs among the poor can be explained by the loss of earnings during illness and absenteeism, coupled with increased spending on transportation and food as part of the care seeking and treatment process. There is 
Table 5 Deterministic sensitivity analysis with prevalence and determinants of catastrophic costs

\begin{tabular}{|c|c|c|c|}
\hline \multirow{2}{*}{$\begin{array}{l}\text { Scenario } \\
(n=1071)\end{array}$} & \multicolumn{2}{|c|}{ Occurrence of catastrophic costs } & \multirow[t]{2}{*}{ Significant determinants* } \\
\hline & $\%$ & $n$ & \\
\hline Base case $(\mathrm{BC})^{*}$ & 27 & 294 & $\begin{array}{l}\text { Pre TB exp } \\
\text { Hospitalization } \\
\text { Facility type } \\
\text { Treatment delay } \\
\text { BMI }\end{array}$ \\
\hline $10 \%$ threshold & 54.3 & 582 & $\begin{array}{l}\text { Pre TB exp } \\
\text { Hospitalization } \\
\text { BMI }\end{array}$ \\
\hline $40 \%$ threshold & 12.8 & 137 & $\begin{array}{l}\text { Similar to base case } \\
\text { Age }\end{array}$ \\
\hline Conservative estimate, direct costs*** & 20.9 & 224 & Similar to base case \\
\hline
\end{tabular}

*Base case represents total costs/household expenditure; threshold of 20\%, **Pre-TB exp=pre-TB annual household expenditure quintiles, BM/body mass index; ***Represents direct costs/household expenditure; threshold at $20 \%$

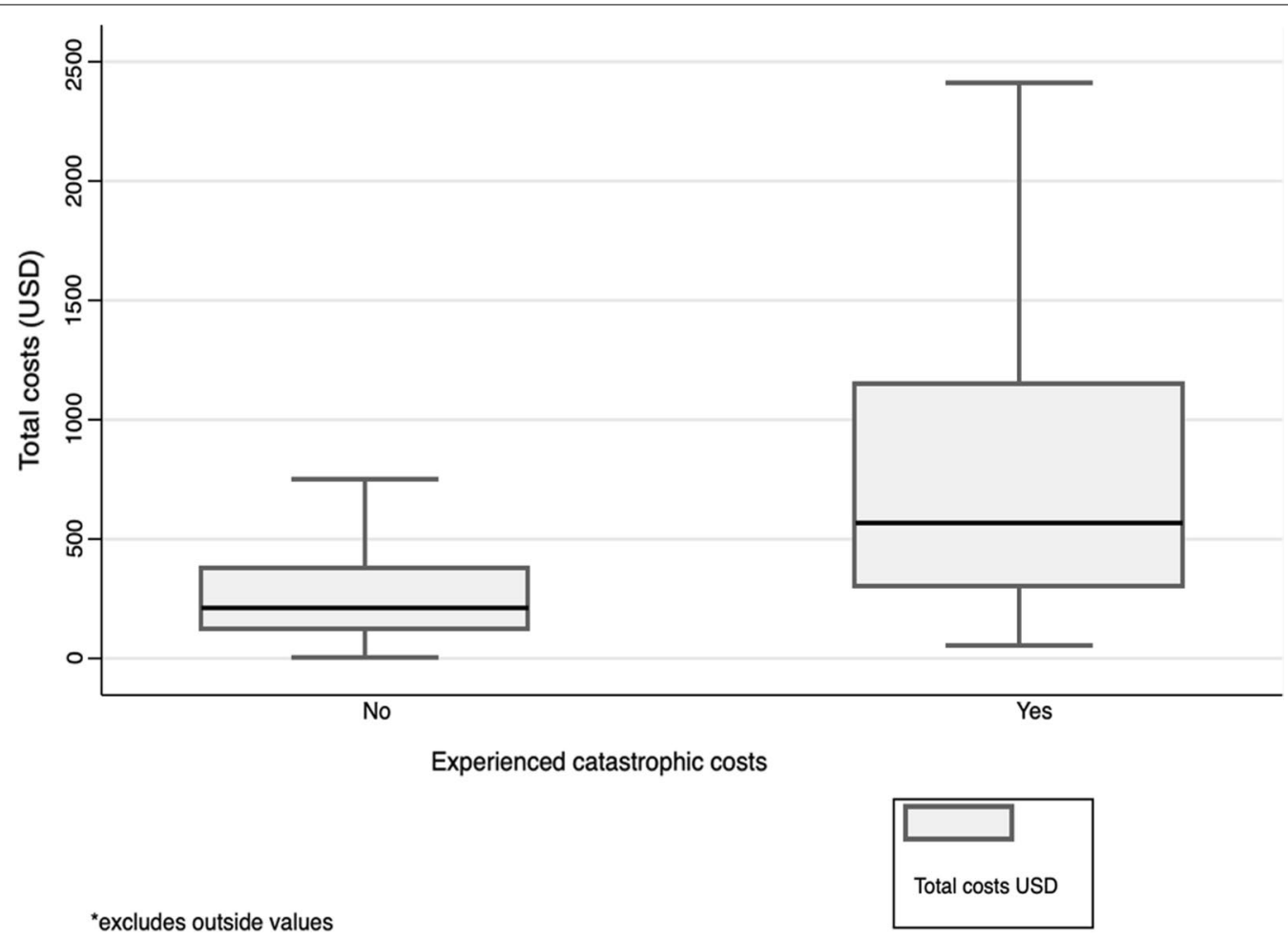

Fig. 3 A comparison of total costs by occurrence of catastrophic costs

low coverage of social protection measures such as health insurance and insurance against income loss when sick in Kenya [47, 48]. The informal sector, which employed $80 \%$ of Kenyans in 2016 [49], is associated with low and irregular pay. The low pay poses a challenge for contributory health insurance schemes [50]. Additionally, paid sick leave is uncommon in the informal sector [51]. The findings of this study indicate that targeting the lower income households for social protection interventions may protect them from catastrophic costs.

\section{Catastrophic costs and disease severity}

Although a small number of participants in this study reported having been hospitalized $(n=6)$, five $(83 \%)$ of them incurred catastrophic costs. These finding are similar to other studies in Uganda [24], and India [52]. This may be attributed to costs like the bed fee 
and additional treatment which are not covered by the TB programme. Additionally, family members or treatment supporters may incur OOP costs for transportation, accommodation, in addition to missing out on their income earning activities. That only $0.6 \%$ of patients were hospitalized may indicate inaccessibility of services for poor patients. The TB care model in Kenya is predominantly community-based DOTS [22], with hospitalization for those with life-threatening symptoms requiring care such as oxygen therapy or intravenous fluid support. Since there is no literature available on the expected hospitalization rates for TB patients, it is difficult to compare with other settings. Nevertheless, these findings could imply that wealthier patient populations are able to afford inpatient care, compared to the poorer patients. In this study, hospitalization and household expenditure have no significant association. However, there is a significant association between hospitalization and seeking care at a private facility. Previous studies in Kenya also demonstrated pro-rich inequality in access to inpatient care and private facilities utilization for generalized illness $[53,54]$.

Low BMI is associated with a higher occurrence of catastrophic costs. Similar findings were reported in Ghana [55] and may be explained by the need to spend more on nutritious food and specialized diets [13]. Malnutrition among TB patients is also associated with more severe TB disease $[56,57]$ and may affect treatment outcomes
$[58,59]$ or even predispose to adverse effects [60], all factors that may increase costs of care. A study in Kenya showed that TB patients who received nutritional support had higher chance of completing their treatment [61].

\section{Catastrophic costs and health-seeking characteristics}

Despite free TB diagnosis and medicines even in private facilities, receiving care in these facilities was associated with a higher incidence of catastrophic costs. Higher costs in private facilities is consistent with findings in Nigeria [62]. This may be explained by extra medical costs at the private facilities which are not included in the NTP package made available to private providers. Continued support for subsidized care at private hospital is important to increase patient access to TB care. However, there is need to explore the extra costs in private facilities and how they hinder access to care.

Delayed treatment initiation is a significant determinant for catastrophic costs in this study. About $24 \%$ of participants with catastrophic costs waited longer than four weeks after onset of symptoms to start treatment. Severe symptoms, increased need for hospitalization, more expensive non-TB treatment or even more frequent visits to the facilities may partially explain why delayed treatment initiation was associated [63-65]. Similar findings have been reported in other studies, associated with multiple visits to inappropriate providers; including formal providers that do not have the capacity to screen for

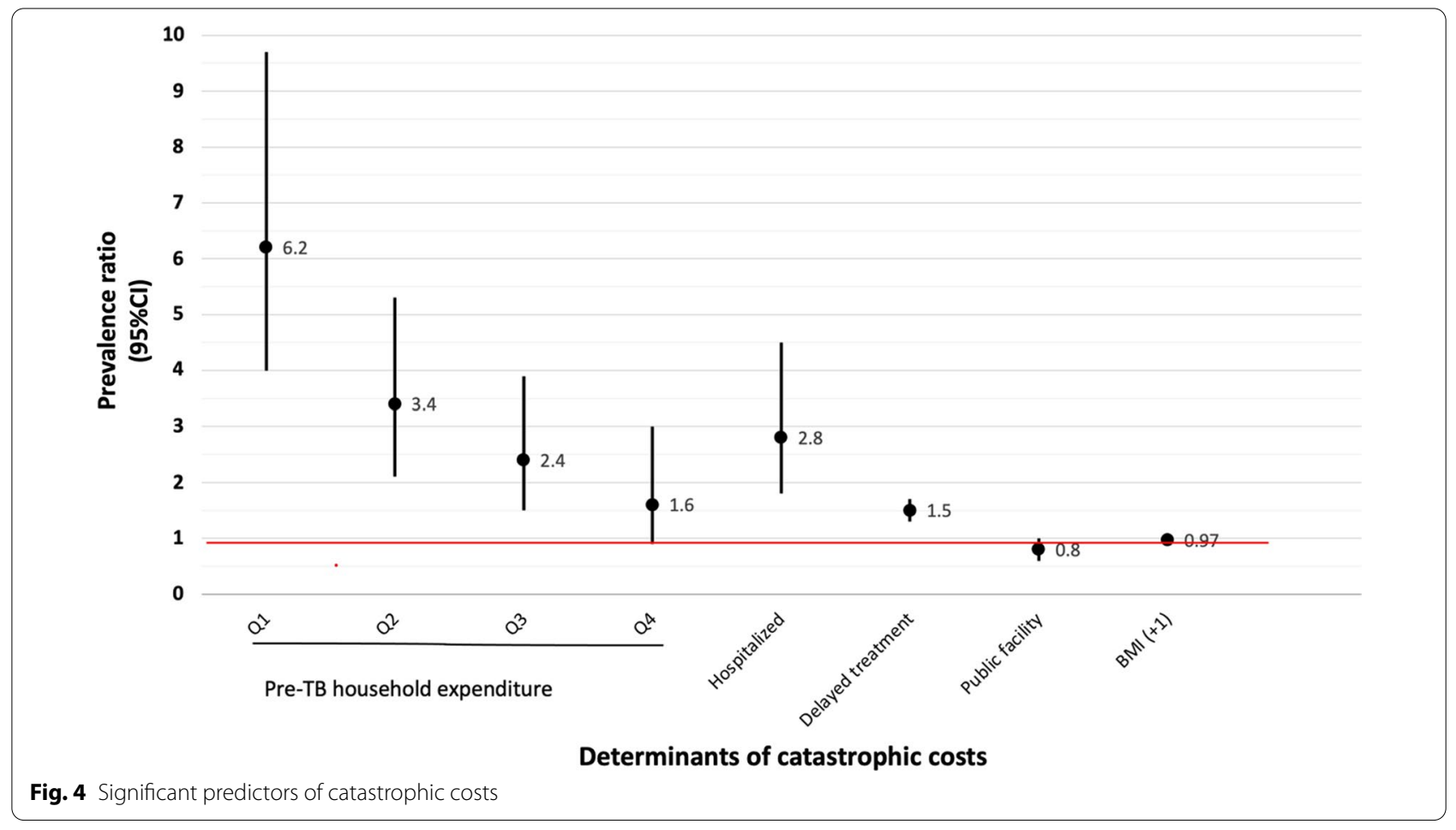


TB or are untrained to recognize TB symptoms or informal providers such as traditional healers [24, 35, 66]. A patient pathway analysis conducted in Kenya, showed that although majority of patients (84\%) seek care within a formal health facility, only $43 \%$ of the facilities had the capacity to diagnose TB and another $45 \%$ could support TB treatment [18]. This leads to the health system delay in starting treatment. On the other hand, patient factors such as economic status, beliefs and stigma also contribute to a delay in seeking care [67]. There is a need to further explore contextualized barriers to seeking and receiving care as a preventive measure for catastrophic costs.

\section{Unexpected findings}

This study differed from existing literature regarding the association of catastrophic costs with sex [24, 45], HIV co-infection [24, 52, 62] and household size [21]. In this study, the patient's sex was not a significant determinant of catastrophic costs. This may be due to the measurement process: Household expenditure and wages to quantify indirect costs were not sensitive to patient's sex. This observation, may also be attributed to the empowerment of women in Kenya regarding family spending and decision-making [68]. A comparison of gender indices shows significant differences in women decision-making over the household spending and their health [69].

Although HIV is associated with treatment delay and X-ray testing, it was not a significant predictor of catastrophic costs. This is contrary to similar studies conducted in Uganda, Nigeria and India [24, 52, 62]. In Kenya additional social support from the HIV programme is provided [18]. In this study, there is a strong association between HIV coinfection and receiving nutritional support which may have alleviated the food costs and therefore resulting in less costs. These findings may also indicate positive integration of $\mathrm{TB} /$ HIV collaborative health service delivery care in Kenya. Finally, household size was not a predictor of catastrophic costs in this study. When DRTB patients were included however, household size was associated with catastrophic costs [21]. Other studies show an association between household size and catastrophic health expenditure for health in Kenya [46]. This may suggest that larger households have a different way of coping with TB costs such as selling assets, borrowing or seeking extra income [54].

\section{Methodological considerations}

This study uses Poisson's regression methods with robust variance to generate prevalence ratios. This method was chosen to generate an accurate estimation of risk [41,
42] and an accurate interpretation of risk [42]. Logistic regression is associated with an over-estimation of risk for a prevalence greater than 10\% [39-41]. Adjusted prevalence ratios and confidence intervals were derived from the final model.

This study took into account both direct and indirect costs, recognizing that time spent seeking care contributes significantly to the burden of TB costs [7]. The indirect costs for this study were calculated using the Human Capital approach due to the low level of formal employment. Although this approach captures all time off work due to the illness and care seeking, it does not take into account household mitigation efforts to compensate for lost income. This may have caused an over-estimation of the productivity losses.

For the denominator, the study used the non-food consumption expenditure as a proxy for household income. This approach provides a better estimate for permanent income in low- and middle-income countries where the rate of formal employment is low [43, 44]. Asset-based wealth was not used since there is a poor correlation with permanent income and tends to overestimates the wealth status of the poor [44, 70].

The study findings can be generalized to DSTB patients in Kenya. Cluster sampling was used in the original survey, taking into account the regional distribution of patients in 2016 and to counter coverage bias. The participants demographic and socio-economic characteristics is representative of the various profiles of DSTB patients in Kenya.

\section{Study limitations}

The study has several limitations. First, the 20\% threshold defined by WHO was used to define catastrophic costs. This threshold may underestimate the burden of catastrophic costs in Kenya based on contextual factors such as the level of poverty and ongoing social protection interventions. However, using the $20 \%$ threshold ensured comparability with other countries. The study incorporated a sensitivity analysis at $10 \%$ and $40 \%$ thresholds to check compatibility and ensure reliability of the results. Second, the patient survey enrolment was facility-based, therefore excluding TB patients who did not seek care at facilities or who may have dropped out of the system prior to treatment. This may lead to late presentation and severe disease and at a higher risk of incurring catastrophic costs when they present for TB care. This study did not take these patients and their determinants into account. The Kenya national TB prevalence survey showed that male patients aged $25-34$ and 65 years and above delayed seeking care even when symptomatic [17]. Additionally, since costs are a barrier to seeking care, it 
could have excluded the very poor who do not make it to the health facilities.

This study looked at predictors of OOP costs borne by patients. However, it would be interesting to explore household coping mechanisms such as selling assets and how these affect the identified predictors of catastrophic costs. Documenting intangible costs such as social consequences, stigma and to value quality of life losses is another opportunity for research. A qualitative study at the community-level seeking to explore the impact of the disease among TB affected patients, families and communities would offer a more in-depth perspective into the social and economic consequences of TB disease. A comparison of these study findings with other diseases with a predilection for poverty, such as COVID-19 would inform us about equity and social determinants of health.

\section{Conclusions}

Despite free TB diagnosis and treatment in Kenya, a significant proportion of patients still incur a substantial financial burden. The predictors of catastrophic costs among DSTB patients and their households include preTB economic status, treatment delay, disease severity and the type of facility where they received care. There are inequities in experiencing catastrophic costs and the poorest are most likely to suffer the medical poverty trap.

Our study has several implications for policymakers in TB. First, interventions beyond the existing free diagnosis and care are needed to protect the DSTB patients against catastrophic costs. Social protection interventions such as cash transfers, access to health insurance coverage, sickness benefits and vouchers could mitigate against catastrophic costs. NTPs implementing social protection interventions should take these predictors into consideration as a guide to identify the most vulnerable populations. Since patients with severe TB were more likely to experience catastrophic costs, it is crucial to identify them earlier. Strengthening TB case finding is key to protecting DSTB patients against catastrophic costs. Interventions such as increasing the capacity of smaller health facilities to diagnose and treat TB or establishing sputum referral networks and active case finding strategies, could reduce costs due to travel and shorten the delay to treatment. Further, community level interventions including education and engagement about TB and available care options may reduce diagnostic delays.

Whereas an umbrella social protection programme that covers all DSTB patients would be ideal, scarce resources necessitate targeting of those who are most at risk. This study has identified patients who are most vulnerable to catastrophic costs.

\begin{abstract}
Abbreviations
BMI: Body mass index; Cl: Confidence interval; DSTB: Drug-sensitive tuberculosis; DRTB: Drug-resistant tuberculosis; DOTS: Daily Observed Treatment Strategy; EPTB: Extra-pulmonary tuberculosis; FBO: Faith Based Organization; GDP: Gross Domestic Product; HDI: Human development index; IQR: Interquartile range; KDHS: Kenya Demographic and Health Survey; MDR-TB: Multi Drug Resistant tuberculosis; MOH: Ministry of Health; NGO: Non-governmental organization; NTP: National TB Programme; OOP: Out-of-pocket; PCS: Patient Cost Survey; PR: Prevalence ratio; PTB: Pulmonary tuberculosis; Q: Quintile; SD: Standard deviation; TB: Tuberculosis; USD: US Dollar; WHO: World Health Organization.
\end{abstract}

\section{Supplementary Information}

The online version contains supplementary material available at https://doi. org/10.1186/s40249-021-00879-4.

Additional file 1: Additional Table 1. Summary of Kenya TB burden, 2018.

Additional file 2: Additional Table 2. Available data by patient group Kenya Patient cost survey (2016).

\section{Acknowledgements}

We thank the National TB Lung and Leprosy programme for availing data for this analysis.

\section{Authors' contributions}

$\mathrm{BK}, \mathrm{JO}, \mathrm{PN}, \mathrm{AR}, \mathrm{KL}$ and $\mathrm{KSA}$ were responsible for developing the study question and the study design. BK conducted the statistical analysis. PN and KS contributed to the statistical analysis. BK drafted the paper with input from all authors. All authors critically reviewed and commented on the paper. All authors read and approved the final paper for publication.

Funding

Open access funding provided by Karolinska Institute.

\section{Availability of data and materials}

The dataset contains sensitive personal information and is not publicly available. For more information, contact the national TB programme Monitoring and Evaluation unit: aibanr@yahoo.com.

\section{Declarations}

Ethics approval and consent to participate

Approval for the Kenya TB patient cost survey was received from AMREF Health Africa Ethics and Scientific review committee (Ref. AMREF P322/2017).

Consent for publication

Not applicable.

\section{Competing interests}

The authors declare that they have no competing interests to declare.

\section{Author details}

${ }^{1}$ Department of Global Public Health, Karolinska Institutet, Stockholm, Sweden. ${ }^{2}$ WHO Collaborating Centre for Tuberculosis and Social Medicine, Stockholm, Sweden. ${ }^{3}$ The Health and Social Protection Action Research \& Knowledge Sharing Network (SPARKS), Stockholm, Sweden. ${ }^{4}$ Centre for Respiratory Disease Research, Kenya Medical Research Institute, Nairobi, Kenya. ${ }^{5}$ Health Economics Research Unit, KEMRI-Wellcome Trust Research Program, 
Nairobi, Kenya. ${ }^{6}$ Monitoring, Evaluation \& Research, National Tuberculosis, Leprosy and Lung Disease Program, Ministry of Health, Nairobi, Kenya.

Received: 21 December 2020 Accepted: 24 June 2021 Published online: 05 July 2021

\section{References}

1. World Health Organization. Global tuberculosis report 2019. Geneva: World Health Organization; 2019.

2. Ahn, Dong, Stop TB Partnership, World Health Organization. Addressing poverty in TB control: options for national TB control programmes. Geneva: World Health Organization; 2005;80.

3. Lönnroth K, Jaramillo E, Williams BG, Dye C, Raviglione M. Drivers of tuberculosis epidemics: the role of risk factors and social determinants. Soc Sci Med. 2009;68:2240-6.

4. Lienhardt C. From exposure to disease: the role of environmental factors in susceptibility to and development of tuberculosis. Epidemiol Rev. 2001;23:288-301.

5. Bates I, Fenton C, Gruber J, Lalloo D, Lara AM, Squire SB, et al. Vulnerability to malaria, tuberculosis, and HIV/AIDS infection and disease. Part 1: determinants operating at individual and household level. Lancet Infect Dis. 2004;4:267-77.

6. Mauch V, Woods N, Kirubi B, Kipruto H, Sitienei J, Klinkenberg E. Assessing access barriers to tuberculosis care with the tool to estimate patients' costs: pilot results from two districts in Kenya. BMC Public Health. 2011:11:43.

7. Tanimura T, Jaramillo E, Weil D, Raviglione M, Lönnroth K. Financial burden for tuberculosis patients in low- and middle-income countries: a systematic review. Eur Respir J. 2014;43:1763-75.

8. Barter DM, Agboola SO, Murray MB, Bärnighausen T. Tuberculosis and poverty: the contribution of patient costs in sub-Saharan Africa-a systematic review. BMC Public Health. 2012;12:980.

9. Whitehead M, Dahlgren G, Evans T. Equity and health sector reforms: can low-income countries escape the medical poverty trap? Lancet. 2001;358:833-6.

10. Executive Board, 134. Global strategy and targets for tuberculosis prevention, care and control after 2015: Report by the Secretariat. World Health Organization; 2015. https://apps.who.int/iris/handle/10665/172828.

11. World Health Organization. Tuberculosis patient cost surveys: a handbook. World Health Organization; 2017. https://apps.who.int/iris/handle/ 10665/259701.

12. Wingfield T, Boccia D, Tovar M, Gavino A, Zevallos K, Montoya R, et al. Defining catastrophic costs and comparing their importance for adverse tuberculosis outcome with multi-drug resistance: a prospective cohort study, Peru. PLoS Med. 2014;11:e1001675.

13. Laurence YV, Griffiths UK, Vassall A. Costs to health services and the patient of treating tuberculosis: a systematic literature review. Pharmacoeconomics. 2015;33:939-55.

14. Mauch V, Bonsu F, Gyapong M, Awini E, Suarez P, Marcelino B, et al. Free tuberculosis diagnosis and treatment are not enough: patient cost evidence from three continents. Int J Tuberc Lung Dis. 2013;17:381-7.

15. Ministry of Health, Kenya. Guideline for integrated tuberculosis, leprosy and lung disease in Kenya, September 2017 edition. 2017.

16. Olaleye A, Beke A. Determinants of survival of patients with tuberculosis in developing countries. Tuberculosis. IntechOpen; 2018. https://www. intechopen.com/books/tuberculosis/determinants-of-survival-of-patie nts-with-tuberculosis-in-developing-countries. Accessed 17Aug 2020.

17. Enos M, Sitienei J, Ong'ang'o J, Mungai B, Kamene M, Wambugu J, et al. Challenges and opportunities of ending TB in Kenya. PLoS One. 2016;2018(13):e0209098.

18. Masini E, Hanson C, Ogoro J, Brown J, Ngari F, Mingkwan P, et al. Using patient-pathway analysis to inform a differentiated program response to tuberculosis: the case of Kenya. J Infect Dis. 2017;216:S714-23.

19. Ministry of Health. National strategic plan for tuberculosis, leprosy and lung health, 2019-2023. 2019.

20. Mailu EW, Owiti P, Ade S, Harries AD, Manzi M, Omesa E, et al. Tuberculosis control activities in the private and public health sectors of Kenya from 2013 to 2017: how do they compare? Trans R Soc Trop Med Hyg. 2019;113:740-8
21. Ministry of Health. The first Kenya Tuberculosis patient cost survey, 2017. 2018. https://www.chskenya.org/wp-content/uploads/2018/07/TB-Patie nt-Cost-Survey-2018.pdf.

22. Ministry of Health, Kenya. Annual report 2018-National Tuberculosis, Leprosy and Lung Disease Program. 2019. https://www.nltp.co.ke/annualreports/.

23. Kenya Social Protection Policy for Tuberculosis and Leprosy patients.

24. Walcott RL, Ingels JB, Corso PS, Zalwango S, Whalen CC, Sekandi JN. There's no such thing as a free TB diagnosis: catastrophic TB costs in Urban Uganda. Glob Public Health. 2020;15:877-88.

25. 2019 Kenya Population and Housing Census Volume II: Distribution of Population by Administrative Units. Kenya Natl Bur Stat. https://www. knbs.or.ke/?wpdmpro=2019-kenya-population-and-housing-census-volume-ii-distribution-of-population-by-administrative-units. Accessed 19 Sep 2020.

26. World Bank. World development indicators. Kenya. World Bank Open Data. 2020. https://data.worldbank.org/country/kenya. Accessed 4 May 2020.

27. UNDP. Human development report, 2018: Kenya. 2019. Available from: http://hdr.undp.org/en/data.

28. Ministry of Health. Kenya health policy 2014-2030. 2014. Available from: http://publications.universalhealth2030.org/uploads/kenya_health_ policy_2014_to_2030.pdf.

29. Faria R, Gomes $\bar{M}$, Epstein D, White IR. A guide to handling missing data in cost-effectiveness analysis conducted within randomised controlled trials. Pharmacoeconomics. 2014;32:1157-70.

30. XE. USD/KES Currency Chart. US dollar to Kenyan shilling rates. xe.com. 2020 https://www.xe.com/currencycharts/?from=USD\&to=KES. Accessed 9 May 2020

31. Bureau of Labour Statistics. CPI inflation calculator. US Bur. Labour Stat. 2018. https://data.bls.gov/cgi-bin/cpicalc.pl?cost1 =100.00\&year1=20170 $6 \&$ year2=202003. Accessed 9 May2020.

32. DeJuan JP, Seater J. The permanent income hypothesis: evidence from the consumer expenditure survey. J Monet Econ. 1999;43:351-76.

33. Carter DJ, Daniel R, Torrens AW, Sanchez MN, Maciel ELN, Bartholomay $P$, et al. The impact of a cash transfer programme on tuberculosis treatment success rate: a quasi-experimental study in Brazil. BMJ Glob Health. 2019:4:e001029.

34. Xu CH, Jeyashree $K$, Shewade HD, Xia YY, Wang LX, Liu Y, et al. Inequity in catastrophic costs among tuberculosis-affected households in China. Infect Dis Poverty. 2019;8:46.

35. Laokri S, Dramaix-Wilmet M, Kassa F, Anagonou S, Dujardin B. Assessing the economic burden of illness for tuberculosis patients in Benin: determinants and consequences of catastrophic health expenditures and inequities. Trop Med Int Health. 2014;19:1249-58.

36. StataCorp. 2017. Stata statistical software: release 15. College Station, TX: StataCorp LLC. https://www.stata.com/support/faqs/resources/citingsoftware-documentation-faqs/. Accessed 27 Apr 2020.

37. Schmidt $\mathrm{CO}$, Kohlmann T. When to use the odds ratio or the relative risk? Int J Public Health. 2008;53:165-7.

38. Coutinho LMS, Scazufca M, Menezes PR. Methods for estimating prevalence ratios in cross-sectional studies. Rev Saude Publica. 2008;42:992-8.

39. Greenland S. Model-based estimation of relative risks and other epidemiologic measures in studies of common outcomes and in case-control studies. Am J Epidemiol. 2004;160:301-5.

40. Thompson ML, Myers JE, Kriebel D. Prevalence odds ratio or prevalence ratio in the analysis of cross sectional data: what is to be done? Occup Environ Med. 1998;55:272-7.

41. Barros AJ, Hirakata VN. Alternatives for logistic regression in cross-sectional studies: an empirical comparison of models that directly estimate the prevalence ratio. BMC Med Res Methodol. 2003;3:21.

42. Martinez BAF, Leotti VB, Silva GSE, Nunes LN, Machado G, Corbellini LG. Odds ratio or prevalence ratio? An overview of reported statistical methods and appropriateness of interpretations in cross-sectional studies with dichotomous outcomes in veterinary medicine. Front Vet Sci. 2017;4:193.

43. Wagstaff A, Flores G, Hsu J, Smitz MF, Chepynoga K, Buisman LR, et al. Progress on catastrophic health spending in 133 countries: a retrospective observational study. Lancet Glob Health. 2018;6:e169-79.

44. Sweeney S, Mukora R, Candfield S, Guinness L, Grant AD, Vassall A. Measuring income for catastrophic cost estimates: limitations and policy implications of current approaches. Soc Sci Med. 2018;215:7-15. 
45. Kemp J. Can Malawi's poor afford free tuberculosis sevices? Patient and household costs associated with a tuberculosis diagnosis in Lilongwe. Bull World Health Organ. 2007;85:580-5

46. Barasa EW, Maina T, Ravishankar N. Assessing the impoverishing effects, and factors associated with the incidence of catastrophic health care payments in Kenya. Int J Equity Health. 2017;16:31.

47. International Labour Organization. World social protection report 2017-19: universal social protection to achieve the sustainable development goals. Geneva: International Labour Organization; 2017. p. 454.

48. Kazungu JS, Barasa EW. Examining levels, distribution and correlates of health insurance coverage in Kenya. Trop Med Int Health. 2017:22:1175-85.

49. Institute of Economic Affairs. Economic burden of the Informal sector. Inst Econ Aff. 2016. https://www.ieakenya.or.ke/number_of_the_week/ economic-burden-of-the-informal-sector. Accessed 5 May 2020.

50. Lagomarsino G, Garabrant A, Adyas A, Muga R, Otoo N. Moving towards universal health coverage: health insurance reforms in nine developing countries in Africa and Asia. Lancet. 2012;380:933-43.

51. ILO. Extending social security coverage to workers in the informal economy: lessons from international experience. International Labour Organization; 2019. https://www.social-protection.org/gimi/RessourceP DF.action?id=55728. Accessed 9 May 2020.

52. Prasanna T, Jeyashree K, Chinnakali P, Bahurupi Y, Vasudevan K, Das M Catastrophic costs of tuberculosis care: a mixed methods study from Puducherry, India. Glob Health Action. 2018;11:1477493.

53. Ilinca S, Di Giorgio L, Salari P, Chuma J. Socio-economic inequality and inequity in use of health care services in Kenya: evidence from the fourth Kenya household health expenditure and utilization survey. Int J Equity Health. 2019;18:196.

54. Salari P, Di Giorgio L, Ilinca S, Chuma J. The catastrophic and impoverishing effects of out-of-pocket healthcare payments in Kenya, 2018. BMJ Glob Health. 2019;4:e001809.

55. Pedrazzoli D, Siroka A, Boccia D, Bonsu F, Nartey K, Houben R, et al. How affordable is TB care? Findings from a nationwide TB patient cost survey in Ghana. Trop Med Int Health. 2018;23:870-8.

56. Putri FA, Burhan E, Nawas A, Soepandi PZ, Sutoyo DK, Agustin H, et al. Body mass index predictive of sputum culture conversion among MDRTB patients in Indonesia. Int J Tuberc Lung Dis. 2014;18:564-70.

57. van Lettow M, Kumwenda JJ, Harries AD, Whalen CC, Taha TE, Kumwenda $\mathrm{N}$, et al. Malnutrition and the severity of lung disease in adults with pulmonary tuberculosis in Malawi. Int J Tuberc Lung Dis. 2004;8:211-7.

58. Bhargava A, Chatterjee M, Jain Y, Chatterjee B, Kataria A, Bhargava M, et al. Nutritional Status of adult patients with pulmonary tuberculosis in rural Central India and its association with mortality. PLoS One. 2013:8:e77979.
59. Birlie A, Tesfaw G, Dejene T, Woldemichael K. Time to death and associated factors among tuberculosis patients in Dangila Woreda, Northwest Ethiopia. PLoS One. 2015;10:e0144244.

60. Warmelink I, ten Hacken NH, van der Werf TS, van Altena R. Weight loss during tuberculosis treatment is an important risk factor for druginduced hepatotoxicity. Br J Nutr. 2011;105:400-8.

61. Mansour O, Masini EO, Kim B-SJ, Kamene M, Githiomi MM, Hanson $\mathrm{CL}$. Impact of a national nutritional support programme on loss to follow-up after tuberculosis diagnosis in Kenya. Int J Tuberc Lung Dis. 2018;22:649-54.

62. Ukwaja KN, Alobu I, Lgwenyi C, Hopewell PC. The high cost of free tuberculosis services: patient and household costs associated with tuberculosis care in Ebonyi State, Nigeria. PLoS One. 2013;8:e73134.

63. Virenfeldt J, Rudolf F, Camara C, Furtado A, Gomes V, Aaby P, et al. Treatment delay affects clinical severity of tuberculosis: a longitudinal cohort study. BMJ Open. 2014:4:e004818.

64. Ravimohan S, Kornfeld H, Weissman D, Bisson GP. Tuberculosis and lung damage: from epidemiology to pathophysiology. Eur Respir Rev. 2018;27:170077.

65. Asres A, Jerene D, Deressa W. Delays to treatment initiation is associated with tuberculosis treatment outcomes among patients on directly observed treatment short course in Southwest Ethiopia: a follow-up study. BMC Pulm Med. 2018;18:64

66. Abimbola S, Ukwaja KN, Onyedum CC, Negin J, Jan S, Martiniuk ALC. Transaction costs of access to health care: implications of the careseeking pathways of tuberculosis patients for health system governance in Nigeria. Glob Public Health. 2015:10:1060-77.

67. Getnet F, Demissie M, Assefa N, Mengistie B, Worku A. Delay in diagnosis of pulmonary tuberculosis in low-and middle-income settings: systematic review and meta-analysis. BMC Pulm Med. 2017;17:202.

68. Kenya National Bureau of Statistics, Ministry of Health/Kenya, National AIDS Control Council/Kenya, Kenya Medical Research Institute, National Council for Population and Development/Kenya. Kenya Demographic and Health Survey 2014. Rockville, MD, USA; 2015. Available from: http:// dhsprogram.com/pubs/pdf/FR308/FR308.pdf.

69. Ewerling F, Lynch JW, Victora CG, van Eerdewijk A, Tyszler M, Barros AJD. The SWPER index for women's empowerment in Africa: development and validation of an index based on survey data. Lancet Glob Health. 2017;5:e916-23.

70. Howe LD, Hargreaves JR, Huttly SR. Issues in the construction of wealth indices for the measurement of socio-economic position in low-income countries. Emerg Themes Epidemiol. 2008;5:3.
Ready to submit your research? Choose BMC and benefit from:

- fast, convenient online submission

- thorough peer review by experienced researchers in your field

- rapid publication on acceptance

- support for research data, including large and complex data types

- gold Open Access which fosters wider collaboration and increased citations

- maximum visibility for your research: over $100 \mathrm{M}$ website views per year

At BMC, research is always in progress.

Learn more biomedcentral.com/submissions 